\title{
INTENSI KONSUMEN TERHADAP KOSMETIK DAN PRODUK SKINCARE HALAL DI INDONESIA: PENDEKATAN THEORY OF PLANNED BEHAVIOR
}

Indah Wahyuningsih

indahningsihwahyu@gmail.com

Pascasarjana Universitas Indonesia

Received: 18 April 2018

Final Acepted: 24 Mei 2018

Published Online: Juni 2018

Keywords:

halal, cosmetics, skincare products, cunsumers purchase intention, theory of planned behavior

Corresponding Authors:

Indah Wahyuningsih

\begin{abstract}
This study aims to analyze the factors that influence consumer intention to halal cosmetics and skincare products in Indonesia. Data were collected through questionnaires, 120 responses were obtained from halal cosmetics and skincare products consumers in Indonesia. This study uses quantitative and explanatory methods which are analyzed using multiple linear regression with the SPSS software. The results showed that the attitude, subjective norms and perceptions of behavioral control positively and significantly influenced the intention of consumers to buy cosmetics and halal skincare products in Indonesia. By learning the intention of consumers can understand the market potential of the cosmetics and skincare products industry so that it can stimulate the growth of the cosmetics and skincare products industry in Indonesia and the world.
\end{abstract}

\begin{abstract}
ABSTRAK
ABSTRAK

Penelitian ini bertujuan untuk menganalisis faktor-faktor yang mempengaruhi intensi konsumen terhadap kosmetik dan produk skincare halal di Indonesia. Pengumpulan data dilakukan dengan menggunakan kuesioner, 120 tanggapan diperoleh dari konsumen kosmetik dan produk skincare halal di seluruh Indonesia. Penelitian ini menggunakan metode kuantitatif dan eksplanatif yang dianalisis menggunakan regresi linier berganda dengan bantuan software SPSS. Hasil penelitian menunjukan bahwa secara pasial sikap, norma subjektif dan persepsi kontrol perilaku berpengaruh positif dan signifikan terhadap intensi konsumen untuk membeli kosmetik dan produk skincare halal di Indonesia. Dengan mempelajari intensi konsumen dapat memahami potensi pasar industri kosmetik dan produk skincare sehingga dapat merangsang pertumbuhan industri kosmetik dan produk skincare di Indonesia maupun dunia.
\end{abstract}

Kata Kunci: halal, kosmetik, produk skincare, intensi konsumen, theory planned behavior. 


\section{PENDAHULUAN}

Industri halal global diperkirakan bernilai sekitar USD2,3 triliun (tidak termasuk sektor keuangan syariah). Tumbuh pada perkiraan tingkat tahunan $20 \%$, industri ini bernilai sekitar USD560 miliar per tahun. Hal ini membuat industri halal global menjadi salah satu segmen konsumen yang tumbuh paling cepat di dunia. Pasar halal global berkisar 1,8 miliar Muslim, tidak lagi terbatas pada produk makanan. Industri halal kini telah berkembang melampaui sektor makanan, termasuk farmasi, kosmetik, produk kesehatan, peralatan mandi dan peralatan medis serta komponen sektor jasa seperti logistik, pemasaran, cetak dan media elektronik, pengemasan, pencitraan merek, dan pembiayaan (Dar, et al., 2013).

Menurut Institute of Personal Care Science of Australia, industri kosmetik halal global diperkirakan bernilai sekitar USD13 miliar dengan tingkat pertumbuhan tahunan sebesar 12\%. Saat ini pasar kosmetik halal merupakan $11 \%$ dari total industri halal global. Berdasarkan laporan Allied Market Research (2016) pasar kosmetik global diperkirakan akan mencapai nilai USD429 miliar pada tahun 2022. Para ahli meramalkan bahwa pasar kosmetik global akan menjadi sektor yang menguntungkan menyusul sektor makanan halal. Permintaan yang besar terhadap kosmetik dan produk skincare halal digerakan oleh demografi penduduk Muslim muda yang sadar agama dan dinamis. Konsep halal dalam kosmetik dan produk skincare sendiri tidak hanya menyangkut aspek produksi, seperti bahan-bahan yang digunakan, tetapi juga menyangkut proses pengemasan, manufaktur, pengiriman dan distribusi harus sesuai dengan syariah.

Pasar kosmetik dan produk skincare halal sedang populer di Asia dan Timur Tengah. Di Asia, khususnya Malaysia dan Indonesia telah memperlihatkan minat yang tinggi terhadap kosmetik halal. Indonesia sebagai negara dengan populasi Muslim terbesar di dunia dengan $88 \%$ dari 258 juta penduduk beragama Islam. Sebagai negara dengan populasi Muslim terbesar di dunia, Indonesia berpotensi untuk menjadi tidak hanya pasar utama tetapi juga produsen utama produk halal. Besarnya potensi pasar produk kosmetik halal, dimanfaatkan oleh produsen kosmetik lokal dan multinasional yang menyasar konsumen muslim dengan strategi membuat produk kosmetik halal. Hal ini sejalan dengan pernyataan bahwa perusahaan yang memenuhi persyaratan syariah Islam dapat meningkatkan pelanggan (Lada et al, 2009). Penting bagi industri kosmetik untuk memenuhi kebutuhan konsumen dan menghasilkan keuntungan serta memenuhi tanggung jawab sosial untuk memuaskan konsumen yang sadar akan kesehatan (Teng dan Jamaliah, 2013).

Untuk menyiapkan rencana bisnis untuk menembus pasar potensial, pemasar lokal dan asing harus memiliki pemahaman yang tepat tentang konsumen dan beroperasi dengan hati-hati untuk menghindari menyinggung konsumen Muslim dan memperoleh pijakan yang baik dan halal 
di pasar seperti Indonesia (Aisyah, 2016). Keinginan untuk mematuhi perintah dalam mengkonsumsi hanya produk halal dapat menciptakan keterlibatan dan pengaruh konsumen dalam membeli atau memilih produk apa yang mereka konsumsi (Salehudin dan Luthfi, 2011). Oleh karenanya penting kiranya untuk menemukan faktor-faktor yang mempengaruhi intensi konsumen terhadap kosmetik dan produk skincare halal sehingga memungkinkan perusahaan untuk memperluas produksinya baik di Indonesia maupun pasar halal global.

Theory of planned behavior digunakan untuk menjelaskan faktor-faktor yang mempengaruhi individu dalam melakukan suatu tindakan atau perilaku. Menurut teori ini perilaku individu diinisiasi oleh intensi terhadap perilaku tersebut. Ada beberapa determinan yang mempengaruhi intensi individu untuk melakukan suatu tindakan atau perilaku, diantaranya adalah sikap, norma subjektif dan persepsi kontol perilaku. Beberapa penelitian terkait (Aziz \& Wahab, 2013) dan (Majid et al. 2015) yang menggunakan pendekatan theory of planned behavior telah dilakukan diberbagai negara termasuk Malaysia dan Pakistan. Aziz dan Wahab (2013) menemukan bahwa norma subjektif, sikap dan persepsi kontrol perilaku mempengaruhi intensi konsumen sebesar 85,6 \%, penelitian ini dilakukan di Malaysia. Penelitian yang dilakukan Majid et. al (2015) di Pakistan menunjukan bahwa 64,3\% intensi konsumen terhadap kosmetik halal dan produk perawatan pribadi dipengaruhi oleh sikap, norma subjektif dan persepsi kontrol perilaku.

Penelitian terkait telah dilakukan di Indonesia Haro, (2018) namun hanya melibatkan reponden berjenis kelamin perempuan. Penelitian ini menunjukan bahwa 48,1\% intensi konsumen bisa dijelakan oleh sikap, norma subjektif dan persepsi kontrol perilaku. Oleh karenanya penelitian lebih lanjut dan mendalam dengan melibatkan tidak hanya responden berjenis kelamin perempuan bisa harus dilakukan. Tujuan dari penelitian ini yang pertama adalah untuk mengetahui sejauh mana theory of planned behavior bisa menjelaskan intensi konsumen terhadap kosmetik dan produk skincare halal di Indonesia. Kedua untuk mengetahui seberapa besar determinan sikap, norma subjektif dan persepsi kontrol perilaku berpengaruh terhadap intensi konsumen terhadap kosmetik dan produk skincare halal di Indonesia.

Berdasarkan uraian di atas, maka tujuan penelitian yang akan dibahas adalah sebagai berikut :

1. Menganalisis pengaruh sikap terhadap intensi konsumen untuk membeli kosmetik dan produk skincare halal.

2. Menganalisis pengaruh norma subjektif terhadap intensi konsumen untuk membeli kosmetik dan produk skincare halal. 
3. Menganalisis pengaruh persepsi kontrol perilaku terhadap minat konsumen untuk membeli kosmetik dan produk skincare halal

\section{KAJIAN TEORI}

\section{Kosmetik dan Produk Skincare Halal}

Halal adalah segala hal yang terbebas dari ikatan larangan dan telah diizinkan oleh syariat Islam untuk melakukannya (Qardhawi, 1993). Halal adalah sebuah konsep aturan prinsip agama Islam, yang digunakan untuk menyatakan bahwa sesuatu hal diijinkan atau dilarang untuk dikonsumsi oleh Muslim dengan dasar dari Al-Qur'an, hadist, atau ijtihad (kesepakatan ulama) (Salahudin, 2010). Konsep halal tidak hanya populer di antara Muslim, tetapi juga di masyarakat dunia secara umum dan mulai diterapkan pada berbagai jenis produk seperti pada makanan, minuman, obat-obatan, toiletries, kosmetik, dan bahkan pada penerapan ilmu keuangan (Lada et al., 2009). Kosmetik terdiri dari semua bentuk produk yang digunakan pada tubuh seseorang untuk mempercantik, membersihkan, dan menyesuaikan tampilan tanpa menyebabkan kerusakan pada tubuh (A. Aziz, Noor, dan Wahab, 2013). Secara umum, halal dalam perspektif industri adalah produk harus bebas dari alkohol dan porcine-by dan turunannya, namun lebih luas dan lebih rumit (Hashim dan Mat Hashim, 2013).

Menurut Fatwa Majelis Ulama Indonesia Nomor: 26 Tahun 2013 tentang Standar Kehalalan Produk Kosmetika dan Penggunaannya, bahan-bahan yang dilarang dalam industri kosmetik diantaranya adalah bahan yang najis atau haram; bahan yang dibuat dengan menggunakan mikroba hasil rekayasa genetika yang melibatkan gen babi atau gen manusia; bahan (bahan baku, bahan aktif, dan/atau bahan tambahan) dari turunan hewan halal (berupa lemak atau lainnya) yang tidak diketahui cara penyembelihannya; bahan dari produk mikrobial yang tidak diketahui media pertumbuhan mikrobanya apakah dari babi, harus dihindari sampai ada kejelasan tentang kehalalan dan kesucian bahannya.

Halal dalam kosmetik dan produk perawatan pribadi meliputi bahan-bahan, masalah keamanan, dan proses produksi (Hashim dan Mat Hashim, 2013). Ini juga mencakup aspek-aspek lain seperti proses manufaktur, penyimpanan, pengemasan dan pengiriman yang harus sesuai dengan persyaratan syariah (Hussin et al., 2013). 


\section{Theory of Planned Behavior}

Landasan teori yang digunakan dalam penelitian ini adalah Theory of Planned Behavior (TPB) yang dikembangkan oleh Ajzen (1985). Teori ini merupakan pengembangan dari Theory of Reasoned Action (TRA) yang dikemukakan oleh Ajzen dan Fishbein (1975). Teori ini digunakan untuk memprediksi perilaku individu secara spesifik. Kinerja individu dari perilaku tertentu ditentukan oleh niatnya untuk melakukan perilaku tersebut. Niat didefinisikan sebagai anteseden langsung perilaku (Ajzen dan Fishbein, 1975). Theory of Planned Behavior (TPB) menjelaskan bahwa sikap terhadap perilaku dan norma subyektif tentang keterlibatan dalam perilaku dianggap mempengaruhi niat pembelian kosmetik halal, Theory of Planned Behavior (TPB) juga mencakup kontrol perilaku yang dirasakan atas keterlibatan dalam perilaku sebagai faktor yang mempengaruhi niat dan perilaku pembelian. Sikap terhadap perilaku adalah evaluasi positif atau negatif dari melakukan perilaku tersebut dan kontrol perilaku yang dirasakan diinformasikan oleh keyakinan tentang kepemilikan peluang dan sumber daya yang dibutuhkan oleh individu untuk terlibat dalam perilaku (Ajzen, 1991).

Theory of Planned Behavior (TPB) mengaitkan perilaku manusia dengan tiga anteseden, sebagai berikut: keyakinan perilaku, yang mengarah pada sikap yang menguntungkan atau tidak menguntungkan terhadap perilaku; keyakinan normatif, yang mengarah pada tekanan sosial yang dirasakan atau norma subyektif; dan kontrol keyakinan, yang mengarah pada kontrol perilaku yang dirasakan. Ketiga faktor ini telah ditemukan secara signifikan mempengaruhi niat perilaku individu (Ajzen, 1991, 2002). Teori ini didasarkan pada asumsi bahwa manusia biasanya bertindak dengan perasaan. Maksudnya adalah bahwa manusia selalu mempertimbangkan segala hal baik dari luar maupun dalam, konsekuensi dan segala hal yang mempengaruhi atau dipengaruhi perilaku tersebut. Segala pertimbangan yang dilakukan manusia tersebut akhirnya akan membawa pada suatu bentuk niat (intention). Intention dapat menentukan dilakukannya atau tidak dilakukannya suatu aksi (Ajzen 1985). 


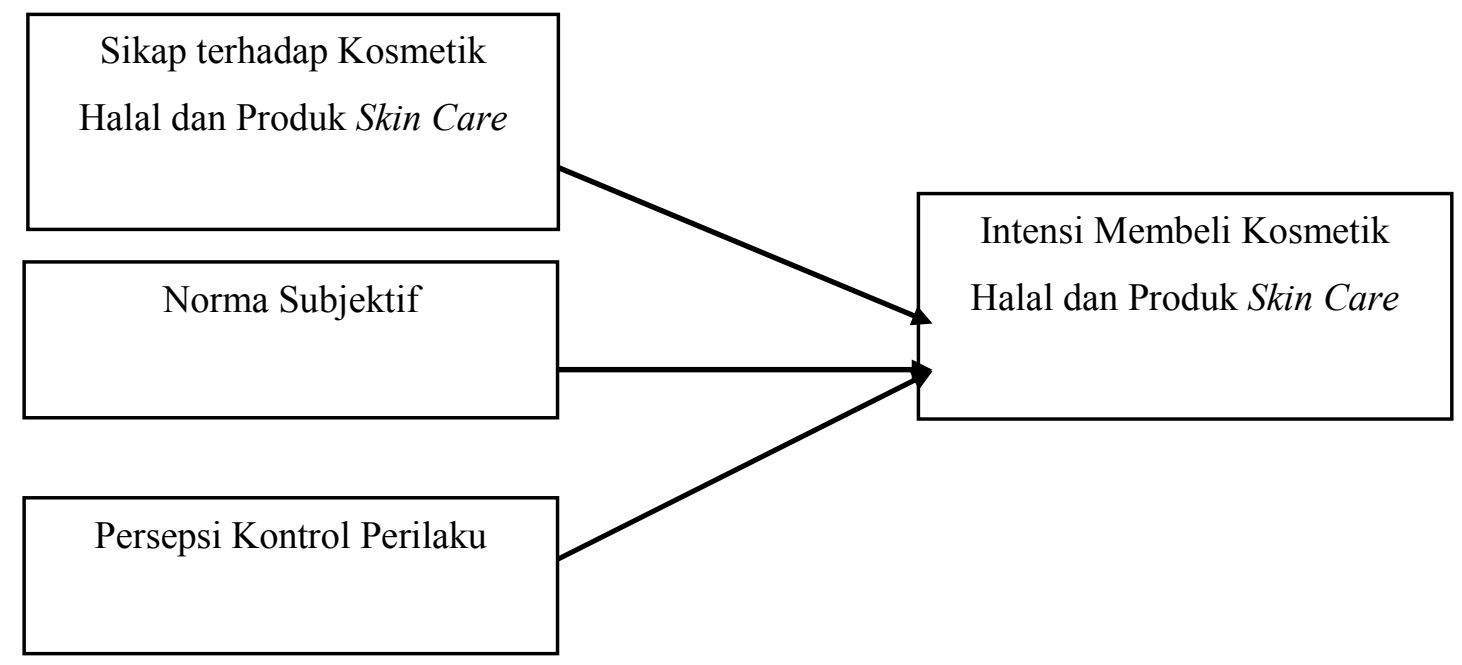

Gambar 1. Theory of Planned Behavior Model (Ajzen, 1991, 2002

\section{Sikap terhadap Kosmetik dan Produk Skincare Halal}

Sikap adalah hasil dari keyakinan perilaku atau keyakinan mengenai kemungkinan konsekuensi dari perilaku tertentu (Ajzen, 2002). Keyakinan dengan penilaian subjektif individu terhadap dunia sekitarnya, pemahaman individu mengenai diri dan lingkungannya, dilakukan dengan cara menghubungkan antara perilaku tertentu dengan berbagai manfaat atau kerugian yang mungkin diperoleh apabila individu melakukan atau tidak melakukannya. Keyakinan ini dapat memperkuat sikap terhadap perilaku itu apabila berdasarkan evaluasi yang dilakukan individu, diperoleh data bahwa perilaku itu dapat memberikan keuntungan baginya (Ramdhani, 2008). Maksudnya adalah evaluasi personal dari individu, baik yang negatif maupun yang positif tentang tindakan tersebut (Fahma, 2014).

Semakin kuat sikap, semakin kuat niatnya, maka ini akan terlihat dalam perilaku keputusan pembelian dan sebaliknya (Ajzen, 2008). Di banyak masyarakat, agama memainkan peran yang berpengaruh dalam membentuk perilaku pembelian produk. Bukti yang cukup menunjukkan bahwa agama dapat mempengaruhi sikap dan perilaku konsumen secara umum, dan pembelian produk atau kebiasaan mengkonsumsi (Rahim dan Junos). Menurut Salehudin dan Luthfi (2011), sikap menunjukkan kepercayaan individu tentang evaluasi pribadi mengenai kepatuhan yang baik terhadap perintah tentang konsumsi halal. Semakin kuat sikap, semakin kuat niat dan keputusan konsumen untuk membeli produk halal. Dengan demikian hipotesis yang diajukan adalah: 
$\mathrm{H}_{1}$ : Sikap berpengaruh positif dan signifikan terhadap intensi konsumen untuk membeli kosmetik dan produk skincare halal.

\section{Norma Subjektif terhadap Kosmetik dan Produk Skincare Halal}

Dalam berperilaku, konsumen tidak dapat dipisahkan dari aktivitas pengambilan keputusan. Keputusan yang dibuat oleh seseorang dibuat atas dasar penilaian mereka sendiri serta atas dasar pertimbangan orang lain yang dianggap penting (Aisyah, 2016). Norma subyektif adalah keyakinan normatif yang terkait erat dengan harapan yang berasal dari orang lain atau sekelompok orang yang dapat sangat mempengaruhi setiap tindakan atau keputusan yang dibuat oleh individu (Mukhtar dan Butt, 2012). Norma subyektif mewakili keyakinan tentang harapan orang lain terhadap individu (Ajzen, 2002). Wanita merasakan tekanan untuk menarik secara fisik. Berkaitan dengan penampilan fisik, teman dekat sering mempengaruhi perilaku wanita yang terkait dengan pembelian kosmetik (Joy dan Venkatesh, 1994). Menurut Azmi et al. (2010), konsumen Muslim mungkin termotivasi untuk memilih produk kosmetik halal karena produk kosmetik yang halal menurut syariah. Penelitian mereka menunjukkan bahwa norma subjektif harus diakui sebagai indikator penting konsumen untuk memilih produk kosmetik halal. Oleh karenanya hipotesisnya adalah:

$\mathrm{H}_{2}$ : Norma Subyektif secara positif dan signifikan mempengaruhi minat konsumen untuk membeli kosmetik dan produk skincare halal.

\section{Persepsi Kontrol Perilaku terhadap Kosmetik dan Produk Skincare Halal}

Persepsi kontrol perilaku adalah persepsi individu mengenai mudah atau sulitnya mewujudkan suatu perilaku tertentu (Ajzen, 2005). Menurut Fahma (2014) Persepsi kontrol perilaku atau biasa disebut dengan kontrol perilaku merupakan fasilitas yang mendukung atau menghambat dilakukannya suatu perilaku, juga dapat diasosiasikan dengan kemampuan individu dalam mengendalikan perilaku. Ajzen (2005) mengemukakan bahwa persepsi kontrol perilaku ditentukan oleh keyakinan individu mengenai ketersediaan sumber daya berupa peralatan, kompatibelitas, kompetensi, dan kesempatan (control belief strength) yang mendukung atau menghambat perilaku yang akan diprediksi dan besarnya peran sumber daya tersebut (power of control factor) dalam mewujudkan perilaku tersebut. Menurut Ajzen (2005) kontrol perilaku yang 
dirasakan dapat secara langsung atau tidak langsung berpengaruh pada niat terhadap perilaku. Oleh karenanya, hipotesis yang diajukan pada penelitian ini adalah:

$\mathrm{H}_{3}$ : Persepsi kontrol perilaku berpengaruh positif dan signifikan terhadap intensi konsumen untuk membeli kosmetik dan produk skincare halal.

\section{Intensi Membeli terhadap Kosmetik dan Produk Skincare Halal}

Kecenderungan seseorang untuk mengambil tindakan membeli berkaitan dengan sikapnya terhadap suatu produk dapat diartikan sebagai intensi (niat) membeli (Hanzaee dan Ramezani, 2011). Niat adalah anteseden dari perilaku yang terlihat di masa depan (Borzooei, M. dan Asgari, 2013). Intensi membeli adalah kecenderungan konsumen konsumen untuk membeli sesuatu atau mengambil tindakan yang berhubungan dengan pembelian yang diukur dengan tingkat kemungkinan melakukan pembelian (Assael, 2004).

\section{Hasil Penelitian Yang Relevan}

Di bawah ini adalah kesimpulan penulis terkait hasil penelitian-penelitian yang pernah dilakukan:

Tabel 1 Penelitian Terdahulu

\begin{tabular}{|c|c|c|c|}
\hline No. & $\begin{array}{l}\text { Nama Peneliti, Tahun } \\
\text { dan Judul Penelitian }\end{array}$ & $\begin{array}{l}\text { Metode } \\
\text { Analisis }\end{array}$ & Hasil Penelitian \\
\hline 1 & $\begin{array}{l}\text { Nur Hadiati Endah } \\
\text { (2014): Perilaku } \\
\text { Pembelian Kosmetik } \\
\text { Berlabel Halal oleh } \\
\text { Konsumen Indonesia }\end{array}$ & $\begin{array}{l}\text { Structural } \\
\text { Equation } \\
\text { Modeling } \\
(\text { SEM) }\end{array}$ & $\begin{array}{l}\text { Hasil penelitian ini menemukan } \\
\text { bahwa tiga anteseden dari intensi } \\
\text { yaitu sikap, norma subjektif dan } \\
\text { persepsi kendali perilaku memiliki } \\
\text { pengaruh yang positif terhadap } \\
\text { intensi konsumen untuk membeli } \\
\text { kosmetik halal. Norma subjektif yang } \\
\text { menggambarkan seberapa besar } \\
\text { konsumen dipengaruhi oleh orang- } \\
\text { orang di sekitarnya merupakan faktor } \\
\text { yang memiliki pengaruh paling besar } \\
\text { dan juga terbukti memiliki hubungan } \\
\text { positif terhadap faktor sikap sehingga } \\
\text { strategi pemasaran produk halal dapat } \\
\text { lebih dioptimalkan melalui } \\
\text { pendekatan kelompok. }\end{array}$ \\
\hline 2 & $\begin{array}{l}\text { Muhammad Bilal } \\
\text { Majid, Irfan Sabir dan } \\
\text { Tooba Ashraf (2015): } \\
\text { Consumer Purchase } \\
\text { Intention towards Halal } \\
\text { Cosmetics \& Personal }\end{array}$ & $\begin{array}{l}\text { Regresi } \\
\text { Linear } \\
\text { Berganda }\end{array}$ & $\begin{array}{l}\text { Penelitian ini menunjukan bahwa } \\
\text { pengetahuan, religiusitas dan label } \\
\text { halal berpengaruh positif terhadap } \\
\text { intensi konsumen perempuan } \\
\text { terhadap kosmetik halal. }\end{array}$ \\
\hline
\end{tabular}




\begin{tabular}{|c|c|c|c|}
\hline & $\begin{array}{l}\text { Care Products in } \\
\text { Pakistan. }\end{array}$ & & \\
\hline 3. & $\begin{array}{l}\text { Siti Sarah } \\
\text { Kusumawardhini, Sri } \\
\text { Rahayu Hijrah Hati, Sri } \\
\text { Daryanti (2016): } \\
\text { Understanding Islamic } \\
\text { Brand Purchase } \\
\text { Intention: The Effects of } \\
\text { Religiosity, Value } \\
\text { Consciousness, and } \\
\text { Product Involvement }\end{array}$ & $\begin{array}{l}\text { Regresi } \\
\text { Linear } \\
\text { Berganda }\end{array}$ & $\begin{array}{l}\text { Penelitian ini menunjukan bahwa } \\
\text { religiusitas, kesadaran nilai dan } \\
\text { keterlibatan produk berpengaruh } \\
\text { terhadap niat membeli merek islami. } \\
\text { Namun religiusitas ternyata tidak } \\
\text { berpengaruh signifikan terhadap niat } \\
\text { membeli merek islami. }\end{array}$ \\
\hline 4. & $\begin{array}{l}\text { Vita Briliana, } \\
\text { Rina Noviana (2016): } \\
\text { The Antecedents and } \\
\text { Outcome of Halal } \\
\text { Cosmetic Products: } \\
\text { A Case Study in Jakarta } \\
\text { Indonesia }\end{array}$ & $\begin{array}{l}\text { Structural } \\
\text { Equation } \\
\text { Modeling } \\
\text { with } \\
\text { Partial } \\
\text { Least } \\
\text { Squares } \\
\text { (SEM- } \\
\text { PLS) }\end{array}$ & $\begin{array}{l}\text { Hasil penelitian menunjukan bahwa } \\
\text { hubungan antara pengetahuan dan } \\
\text { sikap terhadap kosmetik halal adalah } \\
\text { signifikan. Selanjutnya sikap } \\
\text { berpengaruh signifikan terhadap } \\
\text { intensi konsumen untuk membeli } \\
\text { kosmetik halal. }\end{array}$ \\
\hline 5. & $\begin{array}{l}\text { Agnesya Balques, } \\
\text { Bustanul Ar ifin Noer, } \\
\text { dan Varah Nuzulfah } \\
\text { (2017): Analisis Sikap, } \\
\text { Norma Subjektif, dan } \\
\text { Niat Beli } \\
\text { Produk Kosmetik Halal } \\
\text { pada Konsumen } \\
\text { Muslimah } \\
\text { di Surabaya }\end{array}$ & $\begin{array}{l}\text { Structural } \\
\text { Equation } \\
\text { Modeling } \\
(\text { SEM) }\end{array}$ & $\begin{array}{l}\text { Penelitian ini menunjukkan bahwa } \\
\text { halal awareness, religiosity, } \\
\text { sertifikasi halal, dan pemasaran halal } \\
\text { berpengaruh positif terhadap sikap } \\
\text { konsumen produk kosmetik halal. } \\
\text { Hubungan dari keempat faktor } \\
\text { tersebut adalah positif, yang berarti } \\
\text { bahwa semakin baik tingkat } \\
\text { religiosity, sertifikasi halal, dan } \\
\text { pemasaran halal maka akan semakin } \\
\text { membentuk sikap yang positif } \\
\text { konsumen produk kosmetik halal. } \\
\text { Penelitian ini menemukan bahwa niat } \\
\text { beli produk kosmetik halal } \\
\text { dipengaruhi oleh norma subjektif dan } \\
\text { sikap konsumen. }\end{array}$ \\
\hline 6. & $\begin{array}{l}\text { Muniaty Aisyah (2017): } \\
\text { Consumer Demand on } \\
\text { Halal Cosmetics and } \\
\text { Personal Care } \\
\text { Products in Indonesia }\end{array}$ & $\begin{array}{l}\text { Structural } \\
\text { Equation } \\
\text { Modeling } \\
(\text { SEM) }\end{array}$ & $\begin{array}{l}\text { Hasil penelitian ini menunjukkan } \\
\text { bahwa sikap, norma subyektif, } \\
\text { kontrol perilaku yang dirasakan, dan } \\
\text { niat beli konsumen berpengaruh } \\
\text { positif terhadap keputusan konsumen }\end{array}$ \\
\hline
\end{tabular}




\begin{tabular}{|l|l|l|l|}
\hline & & & $\begin{array}{l}\text { membeli kosmetik dan produk } \\
\text { perawatan tubuh berlabel halal. }\end{array}$ \\
\hline 7. & $\begin{array}{l}\text { Nurhadiati Endah, Sri } \\
\text { Daryanti, Sri Rahayu } \\
\text { Hijrah Hati (2017): } \\
\text { Young Adult Muslim } \\
\text { Consumer Intention to } \\
\text { Purchase Halal } \\
\text { Cosmetics: Application } \\
\text { of The Theory of } \\
\text { Planned Behavior }\end{array}$ & $\begin{array}{l}\text { Modeling } \\
\text { (SEM) }\end{array}$ & $\begin{array}{l}\text { Studi menunjukkan bahwa teori } \\
\text { perilaku yang direncanakan dapat } \\
\text { digunakan untuk menjelaskan niat } \\
\text { untuk membeli kosmetik halal oleh } \\
\text { konsumen, di mana sikap, norma } \\
\text { subyektif, dan kontrol perilaku yang } \\
\text { dirasakan memiliki pengaruh positif } \\
\text { pada niat untuk membeli kosmetik } \\
\text { halal. }\end{array}$ \\
\hline 8 & $\begin{array}{l}\text { Andrian Haro (2018): } \\
\text { Determinants of Halal } \\
\text { Cosmetics Purchase } \\
\text { Intention } \text { on Indonesian } \\
\text { Female Muslim } \\
\text { Customer }\end{array}$ & $\begin{array}{l}\text { Regresi } \\
\text { Linear }\end{array}$ & $\begin{array}{l}\text { Penelitian ini menyimpulkan bahwa } \\
\text { sikap, norma subjektif dan } \\
\text { pengetahuan berpengaruh positif dan } \\
\text { signifikan terhadap intensi konsumen } \\
\text { dalam membeli produk kosmetik } \\
\text { halal. }\end{array}$ \\
\hline
\end{tabular}

\section{METODE PENELITIAN}

Metode pengumpulan data yang digunakan dalam penelitian ini adalah metode nonprobability sampling yaitu sebuah teknik sampling yang tidak memberikan kesempatan atau peluang yang sama pada setiap anggota populasi untuk dipilih menjadi sampel (Sarjono dan Julianita, 2011). Berdasarkan konvensi, jumlah minimum sampel yang diperlukan diwakili oleh jumlah item pertanyaan dikalikan lima (Bentler dan Chou, 1987). Konstruk tersebut dioperasionalkan dengan beberapa elemen sebagai berikut: sikap terhadap kosmetik dan produk skincare halal (5 pertanyaan), norma subjektif (6 pertanyaan), persepsi kontrol perilaku (5 pertanyaan), intensi untuk membeli kosmetik halal dan skin care produk (5 pertanyaan). Sehingga jumlah minimum sampel yang dibutuhkan dalam penelitian ini adalah 22 item pertanyaan dikali 5 yaitu 105 sampel. Penelitian ini menggunakan kuesioner sebagai instrument pengumpulan data primer. Kuesioner disebarkan secara online menggunakan Google Form. Dari 146 tanggapan yang masuk dari Google Form ada 120 tanggapan yang bisa digunakan dalam penelitian ini. Dalam penelitian ini, skala Likert 5 poin digunakan untuk mengukur variabel di mana 1 = Sangat Tidak Setuju, 2 = Tidak Setuju, $3=$ Netral, $4=$ Setuju, dan $5=$ Sangat Setuju. Skala Likert digunakan untuk mengukur seberapa kuat subjek setuju dan tidak setuju dengan pernyataan.

Data yang dikumpulkan kemudian dianalisis mengunakaan aplikasi komputer Statistical Package for the Social Sciences (SPSS) versi 23 untuk Mac OS. Analisis dilakukan menggunakan uji normalitas, uji reliabilitas Cronbach Alpha, uji multikolinearitas dan analisis regresi linear 
berganda. Uji normalitas bertujuan untuk menguji apakah dalam model regresi variabel independen memiliki distribusi normal. Uji reliabilitas Cronbach Alpha dilakukan untuk melihat apakah kuesioner memiliki konsistensi jika pengukuran yang dilakukan dengan kuesioner dilakukan secara berulang. Uji normalitas dan reliabilitas merupakan tahap yang harus dilakukan untuk memastikan apakah data yang dikumpulkan bisa dilakukan analisis regresi linear berganda. Uji multikolinieritas dilakukan untuk memastikan multikolinieritas masing-masing data. Data yang baik menunjukan tidak terjadinya hubungan yang kuat (interkorelasi) antar variabel independen sehingga bisa dilanjutkan dengan uji regresi linear berganda.

Analisis regresi linear berganda adalah pengukuran pada penghitungan kontribusi setiap variabel independen terhadap variabel dependen secara bersamaan. Penerapan umumnya adalah untuk mengukur tingkat korelasi antar variabel (Galloway, 2004). Metode kuadrat terkecil digunakan untuk memperkirakan kemiringan dan intersepsi sumbu y dari garis regresi sementara koefisien determinasi (R2) digunakan untuk menguji kontribusi variabel independen terhadap variansi variabel dependen (Fah dan Hoon, 2009).

\section{HASIL DAN PEMBAHASAN}

\section{Uji Reliabilitas}

Uji reliabilitas bertujuan untuk melihat apakah kuesioner memiliki konsistensi jika pengukuran yang dilakukan dengan kuesioner dilakukan secara berulang. Menurut Nunnally (1978) analisis reliabilitas Cronbach harus memiliki nilai yang sama atau melebihi 0,70. Dari hasil uji reliabilitas dapat dilihat di tabel di bawah, setiap variabel memiliki nilai Cronbach Alpha lebih dari 0,70. Dapat disimpulkan bahwa semua variabel reliabel sehingga bisa dilakukan uji regresi linear berganda.

Tabel 2 Hasil Uji Reliabilitas

\begin{tabular}{lcc}
\hline Variabel & Cronbach Alpha & Jumlah Item \\
\hline Sikap & 0,860 & 5 \\
Norma Subjektif & 0,970 & 6 \\
Persepsi Kontrol Perilaku & 0,820 & 5 \\
Intensi untuk Membeli & 0,909 & 5
\end{tabular}

Sumber: Data Primer, 2018, Diolah. 


\section{Demografi Responden}

Seperti yang dapat di lihat di tabel dibawah, mayoritas responden dalam penelitian ini adalah perempuan dengan presentase $88,3 \%$ (106) dan jumlah responden laki-laki dengan presentase $11,7 \%$ (14). Hal ini menunjukan bahwa perempuan adalah mayoritas pengguna kosmetik dan produk skincare. Dari sisi usia, mayoritas responden berada di rentang usia antara 20 sampai dengan 25 tahun, dengan jumlah 77 (64,2\%) responden. Seanjutnya, diikuti oleh rentang usia di bawah 20 tahun dan antara 25 sampai dengan 35 tahun dengan jumlah yang sama, yaitu masing-masing $18(15 \%)$ responden, rentang usia 35 sampai dengan 50 tahun berjumlah $6(5 \%)$ responden dan rentang usia di atas 50 tahun berjumlah $1(0,8 \%)$ responden. Berkenaan dengan status pernikahan, sebagian besar responden berstatus belum menikah, dengan jumlah 101 (84,2\%) responden, diikuti dengan responden yang telah menikah dengan jumlah $16(13,3 \%)$ responden dan yang berstatus janda/duda berjumlah 3 (2,5\%) responden. Terkait tingkat pendidikan responden, 58 $(48,3 \%)$ berpendidikan terakhir S-1, 46 (38,3\%) Sekolah Menengah Atas/Kejuruan, 10 (8,3\%) memiliki kualifikasi pascasarjana (S-2), 4 (3,3\%) Diploma dan 2 (1,7\%) memiliki kualifikasi doktoral (S-3).

Dari segi pekerjaan responden, sebagian besar masih berstatus sebagai mahasiswa, dengan jumlah 60 (50\%) responden, karyawan swasta berjumlah 12 (10\%), wirausaha berjumlah $8(6,7 \%)$, Pegawai Negeri Sipil dengan jumlah 7 (5,8\%) responden, guru dan dosen masing-masing berjumlah $4(3,3 \%)$ responden dan lainnya berjumlah $23(19,2 \%)$ responden. Terkait dengan pendapatan responden, sebagian besar responden memiliki pendapatan perbulan di bawah 1,5 juta rupiah, yaitu sebanyak $68(56,7 \%)$, diikuti dengan yang berpendapatan antara 2,5 sampai 5 juta rupiah berjumlah 23 (19,2\%), responden dengan pendapatan perbulan antara 1,5 sampai dengan 2,5 juta rupiah berjumlah $20(16,7 \%)$, responden dengan perdapatan di atas 10 juta rupiah perbulan berjumlah $6(5 \%)$ responden, dan responden yang berpendapatan antara 5 juta sampai dengan 10 juta perbulan berjumlah $3(2,5 \%)$ responden.

Dapat dilihat bahwa sebagian besar responden adalah perempuan dengan rentang usia 20 sampai dengan 25 tahun. Pada tingkat usia tersebut kesadaran konsumen untuk tampil menarik cenderung lebih tinggi karena didorong dari interaksi sosial yang lebih banyak dibandingkan dengan tingkat usia lain, namun pada tingkat usia tersebut umumnya kondisi keuangan konsumen masih belum mapan sehingga sensitivitas terhadap harga cukup tinggi. Meskipun demikian, konsumen menganggap kosmetik halal sebagai sebuah kebutuhan (Endah, 2014). 
Tabel 3. Demografi Responden

\begin{tabular}{|c|c|c|}
\hline Faktor Demografi & Frekuensi & Presentase \\
\hline \multicolumn{3}{|l|}{ Jenis Kelamin } \\
\hline Perempuan & 106 & $88,3 \%$ \\
\hline Laki-laki & 14 & $11,7 \%$ \\
\hline \multicolumn{3}{|l|}{ Usia } \\
\hline$<20$ Tahun & 18 & $15 \%$ \\
\hline $20<25$ Tahun & 77 & $64,2 \%$ \\
\hline $25<35$ Tahun & 18 & $15 \%$ \\
\hline $35<50$ Tahun & 6 & $5 \%$ \\
\hline$>50$ Tahun & 1 & $0,8 \%$ \\
\hline \multicolumn{3}{|l|}{ Status Pernikahan } \\
\hline Belum Menikah & 101 & $84,2 \%$ \\
\hline Menikah & 16 & $13,3 \%$ \\
\hline Janda/Duda & 3 & $2,5 \%$ \\
\hline \multicolumn{3}{|l|}{ Pendidikan Terakhir } \\
\hline Sekolah Menengah Atas/Kejuruan & 46 & $38,3 \%$ \\
\hline Diploma & 4 & $3,3 \%$ \\
\hline S-1 & 58 & $48,3 \%$ \\
\hline S-2 & 10 & $8,3 \%$ \\
\hline S-3 & 2 & $1,7 \%$ \\
\hline \multicolumn{3}{|l|}{ Pekerjaan } \\
\hline Mahasiswa & 60 & $50 \%$ \\
\hline Wirausaha & 8 & $6,7 \%$ \\
\hline Guru & 4 & $3,3 \%$ \\
\hline PNS & 7 & $5,8 \%$ \\
\hline Dosen & 4 & $3,3 \%$ \\
\hline Karyawan BUMN & 2 & $1,7 \%$ \\
\hline Karyawan Swasta & 12 & $10 \%$ \\
\hline Lainnya & 23 & $19,2 \%$ \\
\hline \multicolumn{3}{|l|}{ Pendapatan Perbulan } \\
\hline$<1,5$ Juta & 68 & $56,7 \%$ \\
\hline $1,5<2,5$ Juta & 20 & $16,7 \%$ \\
\hline 2,5<5 Juta & 23 & $19,2 \%$ \\
\hline $5<10$ Juta & 3 & $2,5 \%$ \\
\hline >10 Juta & 6 & $5 \%$ \\
\hline
\end{tabular}

Sumber: Data Primer, 2018, Diolah. 


\section{Uji Normalitas}

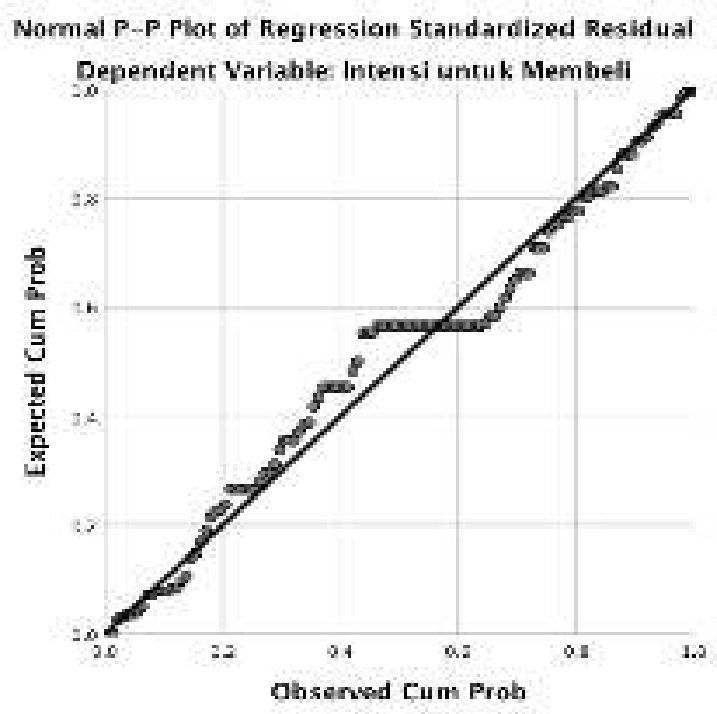

Gambar 2: Grafik Uji Normalitas Data

Sumber: Data Primer, 2018, Diolah.

Uji normalitas bertujuan untuk menguji apakah dalam model regresi variabel independen memiliki distribusi normal. Salah satu cara untuk mendeteksi normalitas data adalah dengan melihat penyebaran data (titik) pada sumbuh diagonal pada grafik. Jika data menyebar disekitar garis diagonal dan mengikuti arah garis diagonal, maka model regresi memenuhi asumsi normalitas. Grafik di atas menunjukan bahwa data menyebar disekitar garis diagonal dan mengikuti arah garis diagonal, dapat disimpulkan bahwa model regresi memenuhi asumsi normalitas.

\section{Uji Multikolinearitas}

Uji multikolerinearitas bertujuan untuk mengetahui apakah terjadi interkorelasi (hubungan yang kuat) antar variabel independen. Jika tidak terjadi interkorelasi antar variabel independen maka model regresi dinyatakan baik dan bisa dilanjutkan dengan uji regresi linear berganda. Tolerance (TOL) dan Variance Inflation Factor (VIP) digunakan untuk mendeteksi ada atau tidaknya gejala mulikolinearitas. Dari haasil uji multikolinieritas antar variabel independen, tidak terjadi gejala multikolinieritas karena semua nilai toleransi (TOL) lebih dari 0,1 dan nilai VIF di bawah 10 . 
Tabel 4: Hasil Uji Multikolinearitas

\begin{tabular}{lcc}
\hline Variabel & Tolerance (TOL) & $\begin{array}{c}\text { Variance Inflation Factor } \\
\text { (VIP) }\end{array}$ \\
\hline Sikap & 0,398 & 2,511 \\
Norma Subjektif & 0,494 & 2,026 \\
Persepsi Kontrol Perilaku & 0,451 & 2,219 \\
\hline
\end{tabular}

Sumber: Data Primer, 2018, Diolah.

\section{Uji Regresi Linear Berganda}

Berdasarkan analisis regresi linear berganda, sikap memiliki nilai koefisien regresi (b) sebesar $(+)$ 0,397, tanda positif berarti sikap memiliki pengaruh positif terhadap intensi konsumen dan nilai signifikansi sebesar $0,000<0,05$ menunjukan bahwa sikap berpengaruh signifikan terhadap intensi. Dapat disimpulkan bahwa sikap berpengaruh positif dan signifikan terhadap intensi konsumen untuk membeli kosmetik dan produk skincare halal. Jadi hasil pengujian hipotesis menjukan bahwa $\mathrm{H}_{1}$ diterima. Hasil penelitian yang sama ditemukan dalam penelitian yang dilakukan oleh Haro (2018), Aziz dan Wahab (2013) serta Majid et al. (2015).

Hasil perhitungan secara parsial menunjukan norma subjektif memiliki koefisien regresi (b) sebesar $(+)$ 0,246 dan signifikansi sebesar $0,000<0,05$. Hal ini menunjukan bahwa norma subjektif berpengaruh positif dan signifikan terhadap intensi konsumen untuk membeli kosmetik dan produk skincare halal. Jadi dapat disimpulkan bahwa hipotesis $\mathrm{H}_{2}$ diterima.

\section{Tabel 5: Hasil Uji Regresi Linear Berganda}

\begin{tabular}{|c|c|c|c|c|c|}
\hline \multicolumn{6}{|c|}{ Coefficients $^{\mathrm{a}}$} \\
\hline \multirow[t]{2}{*}{ Model } & \multicolumn{2}{|c|}{$\begin{array}{c}\text { Unstandardized } \\
\text { Coefficients }\end{array}$} & \multirow{2}{*}{$\begin{array}{c}\text { Standardized } \\
\text { Coefficients }\end{array}$} & \multirow[t]{2}{*}{$\mathrm{t}$} & \multirow[t]{2}{*}{ Sig. } \\
\hline & B & Std. Error & & & \\
\hline 1 (Constant) & $-0,015$ & 1,425 & & $-0,011$ & 0,992 \\
\hline Sikap & 0,397 & 0,093 & 0,347 & 4,247 & 0,000 \\
\hline Norma Subjektif & 0,246 & 0,055 & 0,329 & 4,480 & 0,000 \\
\hline Kontrol Perilaku & 0,305 & 0,089 & 0,263 & 3,421 & 0,001 \\
\hline
\end{tabular}

a. Dependent Variable: Intensi untuk Membeli

Sumber: Data Primer, 2018, Diolah. 
Hasil perhitungan secara parsial menunjukan bahwa persepsi kontrol perilaku memiliki koefisien regresi (b) sebesar $(+)$ 0,305 dan signifikansi sebesar $0,001<0,05$. Hal ini menunjukan bahwa persepsi kontrol perilaku berpengaruh positif dan signifikan terhadap intensi konsumen untuk membeli kosmetik dan produk skincare halal. Jadi dapat disimpulkan bahwa hipotesis $\mathrm{H}_{3}$ diterima.

Tabel 6: Model Summary

\section{Model Summary ${ }^{\mathrm{b}}$}

a. Predictors: (Constant), Kontrol Perilaku, Norma Subjektif, Sikap

b. Dependent Variable: Intensi untuk Membeli

Square Estimate

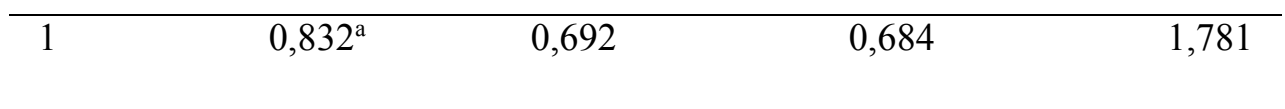

Sumber: Data Primer, 2018, Diolah.

$\mathrm{R}^{2}$ dikenal sebagai koefisien determinasi, mewakili tingkat perubahan dalam variabel dependen yang dapat dijelaskan oleh variabel independen. Hasil koefisien determinasi dalam penelitian ini menggunakan nilai Adjusted R2 sebesar 0,648. Hal ini menunjukkan bahwa 64,8\% variabel intensi konsumen terhadap kosmetik dan produk skincare halal dapat dijelaskan oleh variasi variabel independen dalam model penelitian ini. Sedangkan sisanya sebesar $35,2 \%$ bisa dijelaskan oleh faktor atau variabel lain di luar penelitian ini.

\section{SIMPULAN}

Penelitian ini dilakukan untuk mengetahui pertama, sejauh mana theory of planned behavior menjelaskan intensi konsumen terhadap kosmetik dan produk skincare halal di Indonesia. Kedua, seberapa besar pengaruh sikap, norma subjektif dan persepsi kontrol perilaku mempengaruhi intensi konsumen terhadap kosmetik dan produk skincare halal di Indonesia. Penelitian ini melibatkan data yang diperoleh dari 120 responden di seluruh Indonesia yang memberi tanggapan kuesioner melalui google form. Hasil analisis data menunjukan theory of planned behavior bisa digunakan untuk menjelaskan intensi konsumen di mana sikap, norma subjektif dan persepsi kontrol perilaku berpengaruh secara positif dan signifikan terhadap intensi konsumen terhadap kosmetik dan produk skincare halal di Indonesia. Sebesar 64,8\% intensi 
konsumen terhadap kosmetik dan produk skincare halal bisa dijelaskan oleh sikap, norma subjektif dan persepsi kontrol perilaku. Sementara 32,2\% intensi konsumen dijelaskan oleh determinan lain diluar penelitian ini. Dari sini bisa dilihat bahwa ada determinan diluar sikap, norma subjektif dan persepsi kontrol perilaku yang mempengaruhi intensi terhadap perilaku tertentu. Dalam penelitian ini $64,2 \%$ responden berusia antara 20 sampai dengan 25 tahun dengan 56,7\% responden berpendapatan perbulan di bawah 1,5 juta rupiah. Hal ini bisa dijadikan landasan bagi industri kosmetik dan skincare halal untuk melakukan segmentasi pasar guna memaksimalkan penjualan produk.

\section{DAFTAR PUSTAKA}

Ajzen, I. (1985). From Intentions to Actions: A Theory of Planned Behavior". In J. Kuhl and J. Beckman (Eds.), Action-Control: From Cognition to Behavior (hal. 11-39). Heidelberg: Springer.

Ajzen, I (2008). Consumer Attitudes and Behavior, in C.P. Haugtvedt, P.M. Herr and F. R. Cardes (Eds), Handbook of Consumer Psychology: 525-548. New York: Lawrence Erlbaum Associates.

Azjen, I. (2002), "Perceived Behavioral Control, Self-Efficacy, Locus of Control, and the Theory of Planned Behavior," J. Appl. Soc. Psychol., vol. 32, no. 4, pp. 665-683.

Anas Salahudin. (2010). Bimbingan dan Konseling. Bandung: Pustaka Setia.

Borzooei, M. \& Asgari, M. (2013). The Halal Brand Personality and Its Effect on Purchase Intention. Interdisciplinary Journal of Contemporary Research in Business, 5(3), 481-491.

Fahma, Anindita. 2014 Pengaruh Literasi Halal Terhadap Actual Purchasing Produk Kosmetika Pada Mahasiswi Muslim Fakultas Farmasi Universitas Gadjah Mada Berdasarkan Pendekatan Theory of Planned Behaviour (Tesis). Jogja: Universitas Gadjah Mada.

Fah, L.Y. and K.C. Hoon, 2009. Introduction to computer data analysis with SPSS 16.0 for windows. Selangor: Venton Publishing

Fatwa Majelis Ulama Indonesia Nomor: 26 Tahun 2013 tentang Standar Kehalalan Produk Kosmetika Dan Penggunaannya. https://mui.or.id/wpcontent/uploads/2017/02/No.-26-Standar-Kehalalan-Produk-dan-PenggunaanKosmetika.pdf 
Fishbein, M., \& Ajzen, I. (1975). Belief, Attitude, Intention, and Behavior: An Introduction to Theory and Research, Reading, MA: Addison-Wesley.

Galloway, F.J., 2004. The secrets behind producing meaningful quantitative research: What every foundation official needs. Available from http://studentaffairs.unt.edu/sites/default/files/pdf/rap/Quantitative_Research_

Hashim, P. and D. Mat Hashim, 2013. A review of cosmetic and personal care products: Halal perspective and detection of ingredients. Pertanika Journals of Science and Technology, 21(2): 281-292.

Haro, A. (2018). Determinants of Halal Cosmetics Purchase Intention on Indonesian Female Muslim Customer, Journal of Entrepreneurship, Business and Economics, 6(1), 78-91.

Hanzaee, K. H. dan Ramezani, M. R. (2011). Intention to Halal Products in The World Markets. Interdisciplinary Journal of Research in Business, 1(5), 17-29.

Hussin, S.R., H. Hashim, R.N. Yusof and N.N. Alias, 2013. Relationship between product factors, advertising, and purchase intention of halal cosmetic. Pertanika Journals of Social Sciences \& Humanities, 21(S): 85-100.

Mukhtar, A. and Butt, M. M. (2012). Intention to Choose Halal Products: The Role of Religiosity. Journal of Islamic Marketing, 3(2), 108-120.

Nunnally, J. C. (1978). Psychometric Theory: 2nd Ed. McGraw-Hill. Retrieved from https://books.google.co.id/books?id=AdviswEACAAJ

P. Bentler and C. Chou, "Practical issues in structural equation modeling," Sociol. Methods Res., vol. 16, pp. 78-117, 1987.

Rahim, N.A. \& S. Junos. (2012). The Halal Product Acceptance Model for The Religious Society, Business and Management Quarterly Review, Vol. 3(1): 17-25.

Ramdhani, Neila, Penyusunan Alat Pengukur Berbasis Theory of Planned Behavior, Buletin Psikologi Fakultas Psikologi Universitas Gadjah Mada Volume 19, No. 2, 2011: 55-69.

Salehudin, I. \& B.A. Luthfi. (2011). Marketing Impact of Halal Labeling towards Indonesia Consumer's Behavioral Intention. Asean Marketing Journal, Vol. 3 (1): 35-43. 
Sarjono, H., Julianita, W. (2011). SPSS vs Lisrel: Sebuah pengantar, Aplikasi Untuk Riset. Jakarta: Salemba Empat.

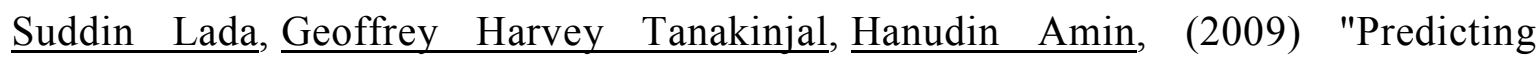
intention to choose halal products using theory of reasoned action", International Journal of Islamic and Middle Eastern Finance and Management, Vol. 2 Issue: 1, pp.66-76, https://doi.org/10.1108/17538390910946276

Teng, P. K., \& Jamaliah, W. W. (2013). Investigating student's awareness and usage intention towards halal labelled cosmetics and personal care products in Malaysia. Paper presented at the 4th International Conference on Business and Economic Research (4 ${ }^{\text {th }}$ ICBER 2013), Indonesia: Bandung. 